\title{
Dossiê
}

Ana Hatherly 


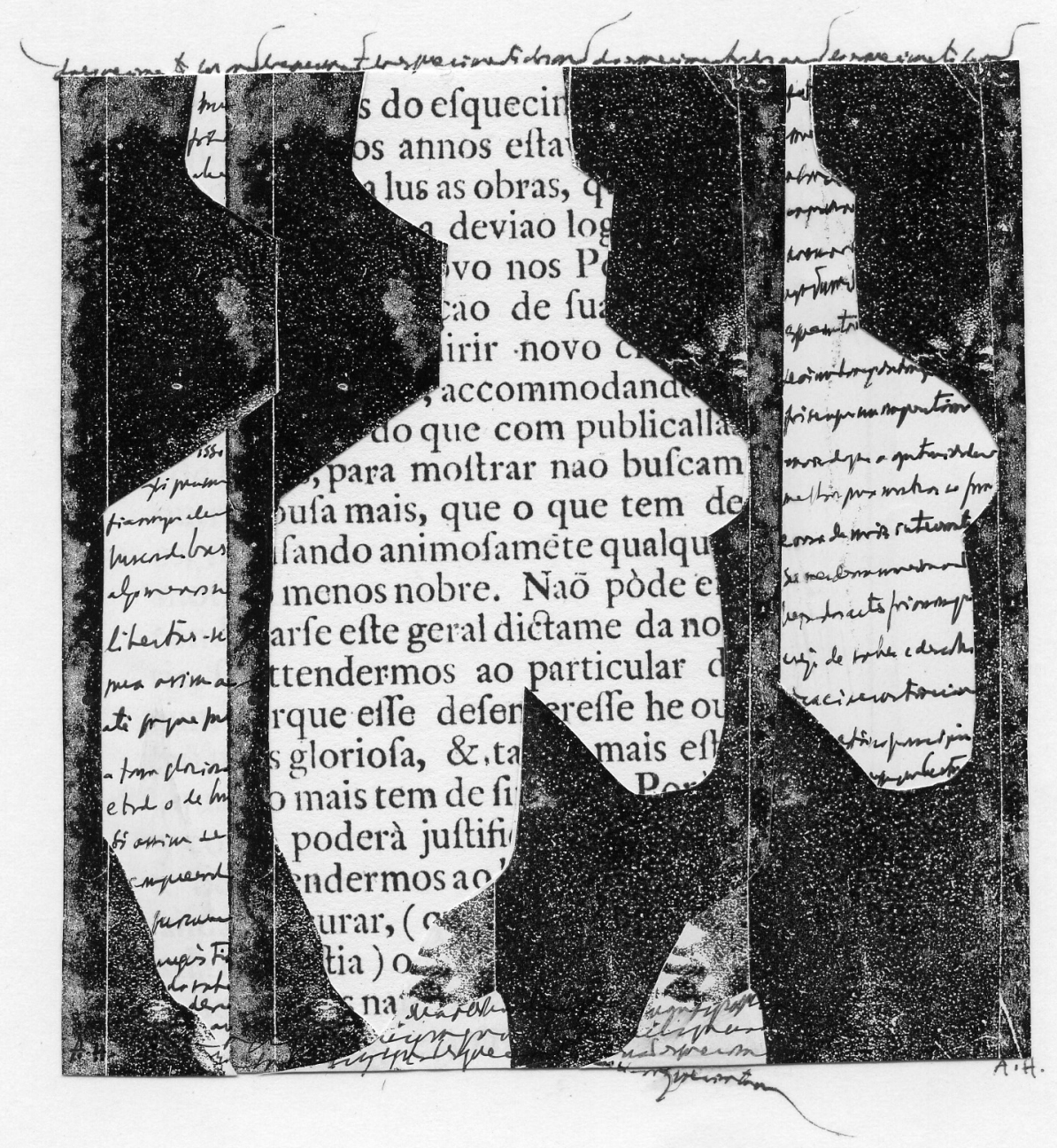




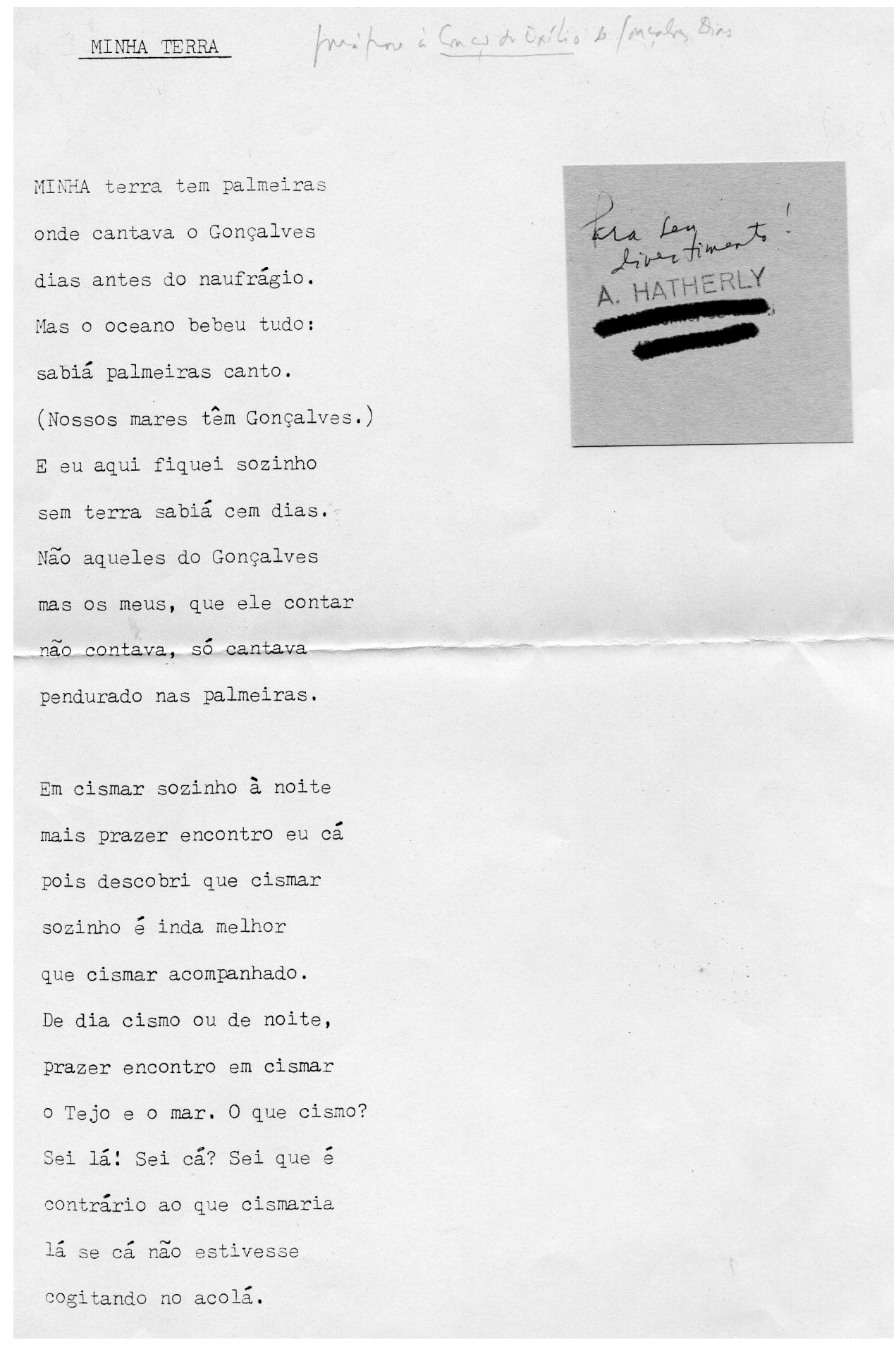


Minha terra tem primores...

Nunca vi um primoreiro,

hão de ser frutos mui raros.

Gonçalves, guarde um pra mim:

Vou ver se tambẻm naufrago

no litoral do... onde mesmo?

Minha terra tem poetas

sensiveis como o Gonçalves

- Casimiro de Abreu

e até Manuel Bandeira,

que passam a vida inteira

ensinando à sua gente:

"Nossa terra tem poetas..."

Ah, muito sentimentais...

Fazem versos comovidos

pois um sabiá (andorinha?)

ouviram cantar não sei onde

um não sei quê (ah:) que vem

não sei como e dói não sei

porque... Mas espere lá:

Estes versos são de cá!

De cá? De quem? Esqueci...

Minha terra tem poetas

memória rimas profetas.

Não permita Deus que eu morra: 
Minha terra tem primores...

Nunca vi um primoreiro,

hão de ser frutos mui raros.

Gonçalves, guarde um pra mim:

Vou ver se também naufrago

no litoral do... onde mesmo?

Minha terra tem poetas

sensíveis como o Gonçalves

- Casimiro de Abreu

e até Manuel Bandeira,

que passam a vida inteira

ensinando à sua gente:

"Nossa terra tem poetas..."

Ah, muito sentimentais...

Fazem versos comovidos

pois um sabiá (andorinha?)

ouviram cantar não sei onde

um não sei quê (ah:) que vem

não sei como e dói não sei

porque... Mas espere lá:

Estes versos são de cá!

De cá? De quem? Esqueci...

Minha terra tem poetas

memória rimas profetas.

Não permita Deus que eu morra: 
E $\circ$ que dizia o Gonçalves,

que queria ser eterno

pra sofrer eternamente

a saudade das palmeiras,

do primor, do sabiá.

Não que eu deseje o contrário

(morro até sem permissão)

mas o que eu queria mesmo

era voltar carregado

de todo todo este amor

que só por cá descobri.

Minha terra tem palmeiras

onde cantava e inda canta

- Gonçalves noite e dia.

Já eu por mim quisera

que meus pobres dias fossem

tão gonçalvos quanto os dele

pra compor uma tenção:

ai dá-me cá, ai toma lá,

a palmeira o sabiá.

Minha terraterramada,

- Gonçalves tem razão:

(do) exílio uma (só) canção. 


\section{Entrevista com Ana Hatherly}

(Horácio Costa, 14 de fevereiro de 2007, PARA A Revista VIA ATLANTICA - ECLLP - FFLCH - USP)

Horácio Costa - Ana, bom dia. Algo me diz que é dia aí em Lisboa (aqui em São Paulo avança a tarde agora, e imagino que você só abrirá o e-mail amanhã de manhã). Começo por mencionar que no ano de 2008 comemoraremos o cinqüentenário da publicação do teu primeiro livro. Por favor, NÃO faça um balanço do teu percurso intelectual nessas cinco décadas. Diga-me simplesmente o que tal evento desperta em você. Quero começar esta entrevista dizendo que me dá muito prazer fazê-la.

ANa Hatherly - A comemoração do cinqüentenário da publicação do meu primeiro livro de poesia, em 1958, hoje em dia, o que me faz sentir é espanto. Entretanto, passou-se tanta coisa! A minha perspectiva em relação ao que é hoje a minha bibliografia activa e passiva surpreende-me. Vejo que trabalhei imenso e acreditando no que estava a fazer. Apesar de ter sofrido bastante, trabalhei sempre com amor. O meu trabalho, quer nas artes, quer nas letras, foi o meu refúgio e o meu consolo. Hoje em dia, quando vejo que meu trabalho é estimado, penso que talvez tenha valido a pena.

Horácio Costa - A tua relação com a linguagem me parece sempre ter sido eminentemente lúdica. Você participou da PoEx e depois fez um excelente rastreio pelo "arquivo" jazente do barroco luso-brasileiro. Teus livros $A$ experiência do prodígio e O ladrão cristalino, entre outros estudos (e a revista Claro-Escuro...), comprovam-no. Vanguarda literária - ou pelo menos, "poesia experimental" - e barroco, eis aqui um tópico que me interessaria muito que você desenvolvesse.

Ana Hatherly - A minha convivência com a linguagem literária e artística foi sempre uma forma particular de relação com a escrita, correspondendo à pesquisa de uma poética pessoal que se transformou em ideolecto. 
A partir dos anos 60, essa atitude tornou-se uma verdadeira inquirição dos aspectos histórico-evolutivos da escrita como "pintura de signos". Não sei se a isso se pode chamar "um acto lúdico" no sentido original do termo. Mas é claro que, quando se chega à projecção do barroco no experimentalismo, o sentido de "lúdico" muda bastante.

A minha relação com a escrita propriamente literária começa antes de eu ter aderido ao movimento da PoEx (Poesia Experimental Portuguesa), em 1964, mas é a ligação a esse movimento que me vai conduzir à prática da Poesia Visual e, paralelamente, nos anos 70-80, à pesquisa da Poesia Visual antiga, cujos resultados publiquei em livros como $A$ experiência do prodígio, $O$ ladrão cristalino, A casa das musas, Poesia incurável e a revista Claro-Escuro, mas já antes disso eu publicara os Mapas da imaginação e da memória, que diz respeito ao meu estudo da caligrafia chinesa arcaica, e $A$ reinvenção da leitura, sobre a importância inovadora da Teoria da Poesia Concreta na defesa da visualidade do texto.

Horácio Costa - Mesmo tópico, outro viés. As nossas condições de "modernidade" pressupõem tal aproximação? Curiosamente, desde o princípio, Augusto de Campos (ainda nos anos 50, se não me engano...) chamava atenção sobre o caráter barroquizante da poesia do seu irmão Haroldo. $\mathrm{Na}$ Espanha e na América Hispânica, por outro lado, o barroco também foi resgatado, tanto na "alta modernidade" como na "pós-modernidade": alguns cubanos (penso em Lezama Lima, Severo Sarduy) fizeram dessa confluência uma espécie de profissão de fé. Haveria mesmo um horizonte que desenhasse um grande arco barroco trans-ibérico? Você se sentiria à vontade nele?

Ana Hatherly - Como Haroldo de Campos bem o demonstrou, por razões de herança cultural, há uma ligação muito importante entre o barroco histórico e a vanguarda experimental do século XX, tanto brasileira como portuguesa. Portanto, a ideia de "um grande arco trans-ibérico" faz todo o sentido em termos culturais, particularmente nessa época. Os experimentalistas portugueses estiveram muito ligados aos concretistas brasileiros, mas não só a eles, porque a presença da vanguarda européia teve sempre neles grande peso, não deixando de ser igualmente uma referência básica tanto para o Brasil como para a América Latina. O vanguardismo do século XX, porém, tornou-se um fenómeno mundial, precursor de uma certa forma de globalização. 
Horácio Costa - Mesmo tópico, ampliado. A tua escritura transforma-se em desenho, em aventura visual, ou é ao revés? A corporalidade da escrita, a visualidade do suporte da mensagem, a liberdade da forma desenhada assumem contornos definíveis? Como é - foi, tem sido - a produção do poema e vice-versa, a do desenho? E na época "da sua reprodutibilidade técnica" (voire, eletrônica)?

ANa Hatherly - O meu trabalho, como já referi, tem por sustentáculo o princípio de que a escrita é "uma pintura de signos". Também posso dizer que é uma aventura física e mental que aspira a uma forma de conhecimento, ou uma aventura que tenta atingir uma forma de perceber, de sentir e comunicar através de signos, que podem ser palavras ou não. Seja qual for o suporte, o instrumento, a técnica ou a matéria, desde que o objectivo final seja transmitir uma ou várias mensagens, aspira a uma forma de comunicação. A criação, essencialmente um acto lúdico de descoberta e de comunicação, se for conscientemente assumida como tal por quem a pratica, conduz a uma experimentação com um leque infinito de formas e sentidos muitas vezes inesperados. É por isso que eu defino o Poeta, no sentido lato do termo, como "um Calculador de Improbabilidades".

HorÁcIo Costa - Experimentalismo + "barroquismo" combina com transgressão. Sim? A quê? E por quê? "A quê", como vejo, remete à questão do cânone literário, especialmente o poético. "Por quê", à ética da inovação em seu bojo; talvez valesse a pena, de uma vez, a esta altura, saber se você teria algo a dizer sobre o fato de ser uma mulher a experimentar e transgredir, se corroborar essa idéia. Gênero feminino e cânone: 'taí uma vertente que eu gostaria que você explorasse.

Ana Hatherly - Sim, sobretudo no que diz respeito ao Cânone Poético. Nós, os poetas da PoEx, sofremos muito com isso. No Brasil também não foi fácil. Toda a mudança de hábitos traz perturbação, e o objectivo de qualquer vanguarda, como sabemos, é precisamente forçar uma mudança, e quanto mais radical, melhor.

Quanto à influência do "género" feminino neste caso não me parece relevante. As verdadeiras vanguardas artísticas têm sido constituídas por um todo bastante unitário nos seus objectivos e métodos. Pode haver leaders, mas não será o "género" a criá-los. Pelo menos nas vanguardas a que me refiro. Mas há outras situações em que o "género" pode ser predominante. 
O fenómeno da Inovação acontece ciclicamente de geração em geração. Às vezes, e podemos comprová-lo, a inovação consiste em andar para trás em vez de andar para a frente, ou simplesmente reciclar, repescar, etc. O meu estudo das origens da poesia visual antiga abriu-me bem os olhos. Actualmente estamos a passar por uma fase de mudança extremamente perturbante por ser tão rápida.

Horácio Costa - Quesito "relações literárias luso-brasileiras". Nós nos conhecemos em Lisboa há uns quinze anos, não? Se não me engano, no Palácio Fronteira, numa leitura minha, ou na semana seguinte, numa da Fiama, da grande e já saudosa Fiama. Naquela noite, o Cesariny (também saudoso: que figura!) me deu um beijo e disse que eu era o primeiro poeta brasileiro que ele beijava (boutade à parte), e mencionou especificamente que tinha se correspondido com todo mundo, de Bandeira ao presente, do lado de cá "del gran charco", como chamam os hispano-americanos ao Atlântico..., mas que nunca tinha conhecido um poeta brasileiro em 3D. Eu fiquei tão escandalizado, não com o beijo, mas com o que essa fala revelava de falta de contato, de presença, entre vocês poetas portugueses e nós poetas brasileiros: como se não houvesse uma política da língua e como se os poetas não tivessem a ver com ela. Os espanhóis e os hispano-americanos nunca se esquecem disso. E nós, Ana? (Ainda) temos saída comunitária?

Ana Hatherly - A fraternidade das relações entre Portugal e Brasil, nomeadamente em termos culturais, tem muito que se lhe diga. Eu, que desde os anos 60 , fui regularmente de dois em dois anos a congressos e encontros culturais de norte a sul do vosso país, fiz muitos amigos e aprendi muito com tudo o que de maravilhoso e de perturbante vi. No final de contas estamos bem longe uns dos outros. Agora parece que há uma grande e inusitada vontade de nos conhecermos melhor. A literatura brasileira teve sempre em Portugal um grande número de admiradores sinceros e conhecedores profundos. Muitos poetas e prosadores brasileiros influenciaram claramente alguns importantes poetas e prosadores portugueses do século XX. No Brasil, o contrário não terá sido verdade. Mas agora tudo está mudando, como vocês dizem...

Horácio Costa - Demorou, mas O Mestre, que você publicou em 63 aí, acaba de ter uma edição brasileira. Me pareceu uma espécie de "éducation sentimentale" heterodoxa, um Émile parodicíssimo (e por isso mesmo, pós-moderno 
avant-la-lettre). Vou bem? No país do Verney do "verdadeiro método de estudar", uma estocada da tua parte aos "métodos", às idealidades da transmissão do conhecimento (literário). Você ensinou toda a vida na universidade aí em Lisboa. Dá para falar sobre O Mestre e ao mesmo tempo do fato de você ser poeta e professora de literatura? Este tópico me diz respeito sobremodo... me dá uma colher de chá, Ana.

Ana Hatherly - Ah, O Mestre! Não sei por que é que essa "novelita" tem resistido tanto. Sei que no Brasil há gerações inteiras de universitários que "cresceram" com O Mestre... Essa obra surgiu num momento especial da minha vida, de que hoje estou longe (ou talvez não...), mas a sua actualidade permaneceu. É uma obra estranha, única, talvez? Pelo menos em Portugal, sim. Alguns críticos nacionais disseram já que se trata de uma das três obras (as outras duas são Os passos em volta, de Herberto Helder, e Rumor branco, de Almeida Faria) que surgiram ao mesmo tempo no início dos 60, e juntas inauguraram uma nova era na ficção portuguesa do século XX.

Horácio Costa - Quesito linguagem poética. Ana/tisana. As tuas Tisanas já andam pelas centenas, e há uma publicação recente delas aí em Portugal. A noção de obra in progress é fun-da-men-tal-men-te moderna, pode você estender-se sobre isso? E a noção de "proema"? Falo sobre a hibridez discursiva, o problema do "registro" literário (que você tão bem maneja em O Mestre, diga-se de passagem...), falo sobre o fazer literário como purgação e remédio (e, em contrapartida, veneno: bem no rastro do Derrida de La pharmacie de Platon). Em resumo, você pode explorar o significado das tuas tisanas e, de quebra, do escrever?

Ana Hatherly - Purgação e remédio? Talvez. Mas não consigo definir as minhas “Tisanas". Digo sempre que são "In-fusões" e não "E-fusões". Mas a verdade é que é muito difícil defini-las. E será mesmo preciso? Digo a quem pergunta que são poemas-em-prosa, micronarrativas, antifábulas, espelhos do Zen, etc. São produto de séculos de saber, isso sim, mas nunca apenas aforismos ou epigramas ou lúdicas acrobacias. A verdade é que, no seu actual conjunto - 463 -, que levei mais de 30 anos a escrever, correspondem a uma obra aberta, que não vai chegar ao fim senão quando eu morrer. Como tantas vezes já o disse, eu sou "um artífice que manipula e interroga a matéria com que trabalha”. De qualquer modo, trata-se de um itinerário de uma vida. 
Horácio Costa - Quesito linguagem poética II. Duas fórmulas: “Tradition and the individual talent" (Eliot) e "tradición y ruptura" (Octavio Paz). Te interessam? Como?

Ana Hatherly - Não muito. Mas às vezes sim. Depende do que estou a fazer ou do que estou a viver. Mas procuro sacudir o mais possível "o peso da cultura".

Horácio COSTA - Você não pára, você parece que sofre da doença do bichocarpinteiro. A quais andaimes está você se dedicando for the time being? Volto ao começo desta inter-vista. Por favor, agora, sim, comente sobre o seu cinqüentenário poético iminente. É chegado o momento memorabilia. Fala, Ana, fala.

Ana Hatherly- Agora estou a preparar a publicação de vários textos inéditos, ensaísticos e documentais, e a elaborar informaticamente, com a ajuda de um assistente, uma bibliografia, activa e passiva - artística, poética, didáctica, etc. -, que parece nunca mais ter fim. Também há o projecto de um novo livro de poemas, intitulado "Poemas Femininos", mas não sei quando sairá. Levo sempre muito tempo a publicar poesia.

Horácio Costa - O Caravaggio tinha um motto: Nec Spe Nec Metu, o que me provoca um frio na espinha. Você tem algum?

ANA Hatherly - Transfiro para aqui a resposta à última questão da alínea anterior: Acho que não irá haver comemoração nenhuma. Os portugueses costumam celebrar os seus artistas só depois de eles terem morrido, e às vezes nem assim.

Por isso, nada espero...

Horácio Costa - Muito obrigado por esta entrevista, Ana Hatherly. Deus te preserve longos anos; a poesia e a língua portuguesa te agradecem o existir. 